\title{
THE USE OF KNOWLEDGE MANAGEMENT SYSTEMS AND EVENT-B MODELLING IN A LEAN ENTERPRISE
}

\author{
- Ladislav Burita, Denisa Hrušecká, Michal Pivnička, Pavel Rosman
}

\begin{abstract}
This paper provides a case study describing an approach to improving the efficiency of an information system (IS) by supporting processes outside the IS, using the ontology-driven knowledge management systems (KMS) as a mini-application in the area of so-called lean enterprise. Lean enterprise is focused on creating a maximal value for final customers while eliminating all kinds of waste and unnecessary costs, which significantly helps to increase the level of its competitiveness. It is about managerial decision-making, which can be in some cases contradictory (solving a local problem can cause a problem in another place). In this paper, we describe the KMS ATOM, which supports the innovation process in a lean enterprise. We show how the risk of wrong decisions due to contradictory effects can be eliminated by implementing a safety-critical system into the traditional IS. Our model is supported by Event-B modelling, a refinement-based formal modelling method, which is successfully used in important areas such as infrastructure, medicine, nuclear engineering and transportation (fire alarm systems, robotic surgery machines, braking systems in transportation, etc.). Nowadays, Event-B modelling is starting to be used for various management decision-making activities, and it is becoming a powerful competitiveness tool. This paper introduces a simple example of how Event-B modelling and its proof obligations can help improve and automate the decision-making process by eliminating potential threats of inefficient decisions.
\end{abstract}

Keywords: knowledge management systems, mini-application, information system, ATOM, Event-B, lean enterprise, lean management, expert system

JEL Classification: D83, M15, M19

\section{INTRODUCTION}

The core idea of lean management is to maximise customer value while minimising costs. The lean approach is about creating more value for customers and eliminating all kinds of waste. A lean enterprise focuses all its processes on continuously increasing customer value. Meeting the requirements of a lean enterprise leads primarily to getting rid of all waste and to the rationalisation of processes, including the processes supported by the enterprise information system (IS). There may, however, be situations in which consistently oriented business information support towards obtaining added value for the customer only results in the rejection of such IS functions in the further development of the company (Chromjakova \& Rajnoha, 2012).

Setting up an IS's missing features is time-consuming and costly, in addition to implementing them on the level of a particular customer. One way to avoid this is to introduce a so-called 
mini-application, which supports processes outside the function of an IS, but cooperates with the corporate IS. We present a mini-application solution to support business innovation based on an ontology-driven knowledge management system (KMS) and a simple example of Event-B modelling to evaluate the efficiency of suggested improvements and innovations.

First, a literature review briefly characterises a lean company with its information support. Further, the literature review discusses the issue of expert systems and Event-B modelling. Both parts of the literature review consider the solution proposed. This paper describes the software (SW) ATOM and the solution of the mini-application. This is followed by a potential extension in the form of the Event-B model with its useful proof obligations. The conclusion summarises the main outcomes of this study.

\section{BACKGOUND AND RELATED WORK}

Before describing the mini-application of an ontology-driven KMS and Event-B model supporting decision-making in this system, we first present the theoretical background of lean management and knowledge-based systems.

\subsection{The Lean Enterprise and Information Systems}

The main goal of any process in the lean enterprise is to provide the best value to its customers with no waste. There are still numerous companies in which only $10 \%$ of the total lead time of any process adds value to final customers (Imai, 2004). In general, lean is about achieving more with less: less effort, space, defects, throughput time, etc. As stated by Smith and Hawkins (2004), it is a necessity to provide the customer with a higher value with less waste in order to stay in business, especially in today's global market. And this is what lean thinking is all about.

Lean thinking changes the approaches in management from local optimisations in separate departments to optimising the whole value stream (flow of products and services), eliminating waste along this flow. Lean enterprise is more flexible and reacts faster to changing customer needs. Furthermore, information management becomes much simpler and accurate in such an environment (Smith \& Hawkins, 2004; Dudbridge, 2011).

Activities leading to the implementation and development of a lean enterprise are difficult to put into practice without implementing an appropriate enterprise IS and applying other components for the information support of the business processes. The practical implementation of the lean principles uses a number of methods and procedures that cannot be operated without knowledge of a specific procedure of the existing processes. It can only ensure a quality IS that receives data about the production and logistics processes in real time (Cerny, 2012).

In business practice, it is apparent that some processes need to be supported by the IS more urgently, but they also need to maintain the independence of the systems. Without this, the organisation fails to be sufficiently flexible, and its processes cannot be sufficiently distinguished from those of competitors working with the same system. A suitable solution is the controlled circulation of mini-applications capable of exchanging data with other ISs. This is actually a fairly common situation that facilitates the management of processes outside the IS. Below are requirements that have to be fulfilled by mini-applications (Petr, 2013): 
- Cooperation with information systems; loading from them data and passing the results back.

- Central management of circulation; the workflow process that delivers the right information at the right time to the right person.

- A user-friendly interface.

- Creating and archiving documents.

The implementation of lean production is popular, but it is demanding and requires a radical change in all production processes in order to obtain competitive advantages. In such cases, universal IS modules with focus on lean production must be available (Cvrkal, 2012).

\subsection{Knowledge-Based Systems and Event-B}

A knowledge-based system or knowledge management system (KMS) is a computer program for solving complex problems using knowledge base and an inference engine. The first knowledgebased systems were rule-based expert systems. An expert system can be characterised as a computer program that mimics the behaviour of a human expert. It is useful especially for solving complex problems by reasoning about knowledge that is usually represented by a set of if-then rules (Smith, 1985; Jackson, 1998).

A critical point of an expert system is knowledge base $(\mathrm{KB})$ refinement. It is a modification of rule-components in an existing knowledge base. Weiss et al. define the main goals of KB refinement as the localisation of specific weaknesses in a KB and improvement of an expert system's performance. In this article, we introduce a refinement-based method for knowledge modelling called Event- $\mathrm{B}$, which is suitable for event-driven reactive systems such as a manufacturing process or other types of business processes.

Event-B is a formal method for system modelling and analysis. It is an extension of B method that was first introduced by Jean-Raymond Abrial in the early 1990s. In comparison with B method, Event-B admits a richer notion of refinement through which the complex interactions between subcomponents may be abstracted in incremental stages. Then, a mathematical proof is used to verify consistency between refinement levels (Abrial, 2010; Métayer et al., 2007).

An Event-B model consists of machines and their events. The state of the model, its validity and transformation is usually described by a set of variables (V), invariants (I), events (E) and their guards $(G)$. A context machine with sets and constants $(C)$ definitions can also be included if needed. Each event is then a guarded command composed by guards and actions as follows: "when $\mathrm{G}(\mathrm{V})$ then $\mathrm{A}(\mathrm{V})$ " (Métayer et al., 2007; Mu, 2013).

\subsection{Implications from the Literature Review}

The search (Imai, 2004) for lean principles and lean enterprises is based on possible situations in which a corporate IS, in order to make savings, includes some features that do not support all business processes, such as various types of production process improvements and innovation. This is confirmed by adapting our systems to the needs of the enterprise (Cerny, 2012). Thus, during the development of the company such functions may be missing, however, their imple- 
mentation in the IS is costly and technologically risky. Such a feature is expected to be replaced by the mini-application.

Reflections on the needs of the practice (Petr, 2013), in which some processes should be supported by the IS, but some independence should also be maintained, support the idea of the implementation of the mini-applications in general. This is true both for complex ERP systems and for the ISs in SMEs. The article also lists requirements for mini-applications, and proposes a solution based on the SW ATOM.

Klečka \& Matějka (2004) note development of the knowledge level of the organisation, which may help KMS implementation in the form of a mini-application (creating conditions). Rasmussen (2015) compares two different worlds of business innovation: marketing and research. The solution to moving the people of these two worlds towards each other is creation of communities of interest (CoI) and development of communication. Both requirements can be based on solutions provided by the ATOM SW.

To make KMS more efficient and reactive, it is useful to automate some of its functions and support a complex problem solving based on the well-modelled knowledge base. There are many different approaches to knowledge modelling. We deal with the Event-B which is quite a new method based on refinement. Several studies prove its positive effects in different areas such as medicine (Weiss, 1986), robotics (Pereverzeva et al., 2012), services (Sayar et al., 2014), etc. We introduce the possibilities of Event-B modelling in combination with KMS system ATOM to support an efficient implementation of suggested improvements and innovation in a lean enterprise.

\section{THE CASE STUDY OF THE MINI-APPLICATION}

The main goal of the case study presented is to show how an ontology-driven mini-application can be used to improve efficiency of IS in a lean enterprise in order to increase its competitiveness. Our results are accompanied by a refinement-based Event-B model presented in the last section.

The core source for the mini-application development and using is the system ATOM (AION CS, 2012), a software (SW) tool for sharing data between any groups of people (co-workers, customers, or friends) via web browsers. It is an ontology-driven web SW that can be used as a construction kit for building knowledge management systems (KMS) with powerful information retrieval without any special knowledge.

This KMS is based on the topic maps (TMs) principle that is standardised in ISO/IEC 13250:2003. TMs principle means that the knowledge representation is intuitive and information is kept in context, which conforms to human thinking. The TMs model consists of the following basic elements: topics, associations between topics and internal or external occurrences of topics (Pepper, 2012).

The methodology of the case study preparation includes three steps:

1. Analysis and modelling of the supported process. 
2. Ontology creation and its implementation.

3. Proof of concept of the mini-application.

\subsection{Analysis and Modelling of the Supported Process}

The analysis of the supported process results in a model that represents understanding of the selected domain. In our example, the selected domain is innovation or production process improvement (further called just innovation). The model of the innovation process includes some subjects or objects (father only objects) and relations between them (see Fig. 1). Explanation of the objects:

- INNOVATION - the description of the proposed or required innovation.

- PROJECT - the approved suggestion of innovation is changed to the project.

- DEPARTMENT - the department that is an object or a subject of the innovation.

- PERSON - a member of a department; the innovation proposer.

The model is prepared in the Visual Understanding Environment (VUE, 2015).

\subsection{Ontology Creation and Implementation}

The ontology of the KMS of the problem domain is created in Schema Editor of the ATOM Studio by drawing or writing it into forms using pre-prepared templates of the mini-application. The functions Search/Export and Import of the ATOM Studio can be applied to exchange data with the IS.

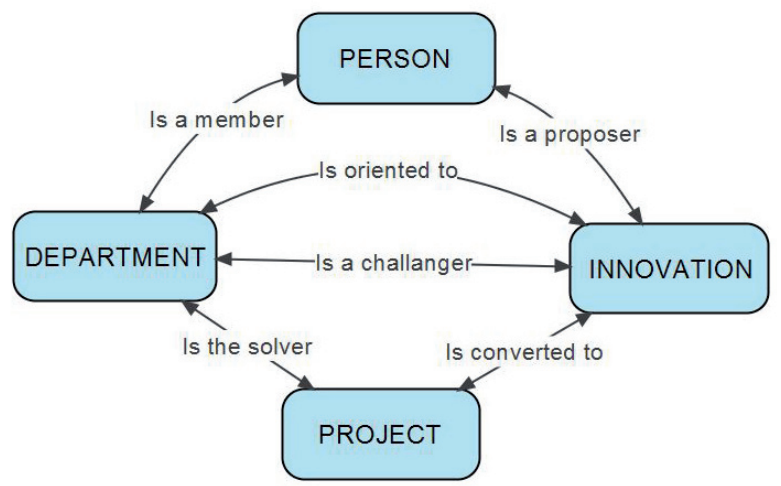

Fig. 1 - Model of the process innovation in VUE. Source: own

The ontology scheme is derived from the model (see Fig. 1); objects of the model are classes of the ontology and relations between objects are association of the ontology. The next step of the ontology definition is the design of characteristics (or properties) of classes and their assignment to the classes (see Tab. 1). 
Tab. 1 - Ontology assignment of characteristics to classes. Source: own

\begin{tabular}{|l|l|l|c|c|c|c|}
\hline Order & Characteristic/class & Data type & Department & Innovation & Person & Project \\
\hline 1 & Date of decision & Date & & $\mathrm{X}$ & & \\
\hline 2 & Date of proposal & Date & & $\mathrm{X}$ & & \\
\hline 3 & Date of start & Date & & & & $\mathrm{X}$ \\
\hline 4 & Date of termination & Date & & & & $\mathrm{X}$ \\
\hline 5 & Function & Text & $\mathrm{X}$ & & $\mathrm{X}$ & \\
\hline 6 & Limitation - factual & Text & & $\mathrm{X}$ & & \\
\hline 7 & $\begin{array}{l}\text { Limitation }- \text { finan- } \\
\text { cial }\end{array}$ & Number & & $\mathrm{X}$ & & \\
\hline 8 & Name or Title & Name & $\mathrm{X}$ & $\mathrm{X}$ & $\mathrm{X}$ & $\mathrm{X}$ \\
\hline 9 & $\begin{array}{l}\text { Objectives of solu- } \\
\text { tion }\end{array}$ & Text & & $\mathrm{X}$ & & $\mathrm{X}$ \\
\hline 10 & Outputs of solution & Text & & $\mathrm{X}$ & & $\mathrm{X}$ \\
\hline 11 & Sources - factual & Text & & $\mathrm{X}$ & & $\mathrm{X}$ \\
\hline 12 & Sources - financial & Number & & $\mathrm{X}$ & & $\mathrm{X}$ \\
\hline 13 & Status & Group-tree & & $\mathrm{X}$ & & \\
\hline 14 & WWW page & URL & $\mathrm{X}$ & & $\mathrm{X}$ & \\
\hline
\end{tabular}

Finally, the ontology definition is implemented in the ATOM Studio environment. The implementation can be carried out using a formulary access or the graphical mode, or their combination.

\subsection{Proof of Concept of the Mini-Application}

The example of development of a mini-application for innovation is based on a fictional medium-sized manufacturing enterprise, producing components for the automotive industry. This example considers two production lines: one is used for refrigeration and air conditioning equipment (Mikulášková, 2013), and the second for metal machining on CNC-controlled machine tools (Vaculíková, 2011).

In case of the first production line, the production process innovation is applied to the process of manufacturing heat exchangers for diesel engines. This process consists of the following operations (Mikulášková, 2013):

1. Spot welding of a cap and a cross piece.

2. Block assembling - assembling a U-shaped setting block from welded spot and gas tubes. The machine is fully automated - the operator just inserts the parts.

3. Paste application - the setting block is moved to pallets which are automatically transported to a pasting machine where a soldering paste is applied.

4. Soldering - the soldering plates that pasted the setting block go through the oven where the paste is melted at approximately 1,000 degrees. Then, the setting block is turned cold by ventilators. 
5. Unloading plates and a seal feeder - this operation is automatic, but a visual inspection by the operator is necessary. The soldered setting blocks are manually set with a solder plate and retained on the belt of the automatic seal feeder.

6. Exchanger assembling - the setting block is assembled together with an aluminium cast.

7. Tightness testing - the assembled exchanger is tested by pressure. Leaking heat exchangers are sent to be repaired. The size is checked as well.

8. Laser marking - a product identification label is added by laser directly to the body casting because of a high temperature in the engine.

9. Blowing - the inner purification of the product using high pressure air. Purity is required when installing the engine.

10.Final inspection and packaging - the immediately purged piece is sealed with foil, visually inspected by the operator, and stored in crates.

After the detailed analysis of the first production process, the following suggestions for innovations are considered:

a) Optimisation of the supply - redesign the supply truck. Customise the size of the truck boxes, achieving a reduction in transport by $30 \%$. Increase the efficiency in cartridge assembling, saving operators. The limit is 3,000 euro.

b) Optimisation of the supply - reducing the transport routes of the supply. Storing waste on the same truck. Increase the efficiency of cartridge assembling, saving operators.

c) Automatic spot welding - new machinery, saving two operators. The limit is 11,000 euro.

In the next production process, various tube connector parts are produced in the following production steps (Vaculíková, 2011):

1. Cutting, tumbling - cutting on a CNC circular saw. Before cutting, it is necessary to adjust the saw to cut the part. The cut parts are piled into two crates and moved immediately to the tumbling device.

2. First milling, tumbling - the milling is performed on a CNC machine with a fixed table. The milling machine is operated by one person working with 12 pieces at the same time.

3. Second milling - in the milling on the CNC machine with a rotary table, there is a milled sleeve. The operator operates the two cutters at each router, generally producing another type of a product. At the same time, there are eight reworked parts.

4. Washing, checking and packing - these operations are carried out by four workers, one wash holds four bins, and the washing programme lasts for 15 minutes. Then, the parts are blown and checked. 


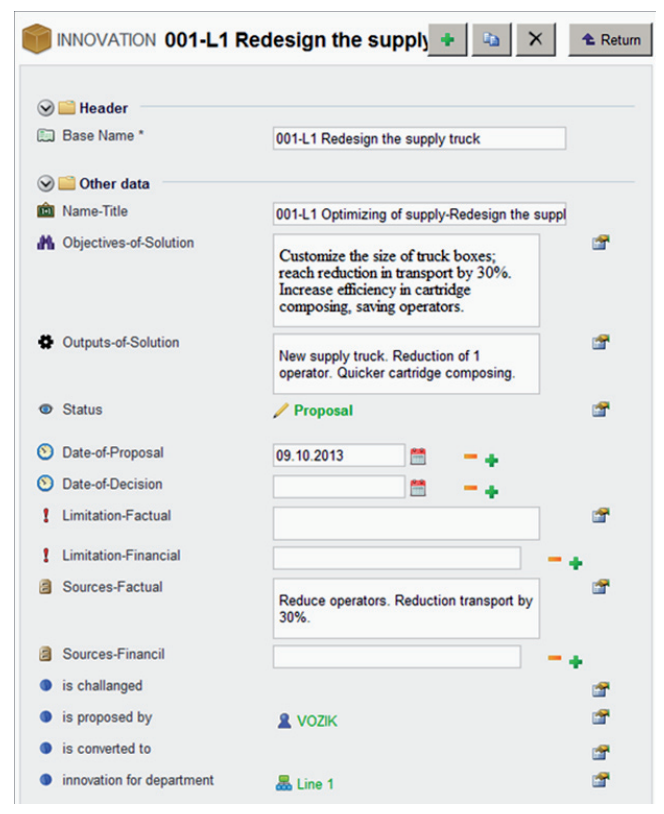

Fig. 2 - Inserting innovation into form. Source: own

A detailed analysis of the second production process shows the potential for improvement and the following innovations are considered:

a) The implementation of a pull system - volume reduction of the manufacturing batch. Batch production for cutting and tumbling. The other production is controlled by the FIFO principle. This shortens the production lead time of 10 days and reduces the work-in-progress inventory by $40 \%$.

b) Layout optimisation - saw and tumbling machines are placed as close as possible to the CNC machine, increasing the put off space on the machines, improving the orientation of the operators and shortening the time of parts around the workplace by $50 \%$.

c) Visualisation of the results of production, implementation of a scheduling board and the material flow controlled by a Karban card.

d) Create a workflow of machine adjustment - make a compensation adjustment tentatively. List the steps of adjustment showing the critical points.

Proposals for innovations are loaded into the mini-application. This, after the consultation with technology, performs a proposal itself. It is esential that the names of the innovation are rather tentative (marking lines) and clear (continuous numbering). Innovations are done by workers and challenges to the technological innovation made by departments or management of the company.

The innovation is structured in the standard form (see Fig. 2). In this form, the innovation is connected to the proposal person or department of challengers and the department towards 
which the innovation is oriented and selected. Innovations can be monitored by the state of challenged or proposed and by those that the leadership has decided will be handled by.

The example in proof of concept shows that the mini-application works quite reliably, is easily manageable by users and fulfils the necessary requirements.

\section{EVENT-B MODELLING}

The ontology-driven KMS supports an integration of different sources of related information and selection of the target knowledge for decision-making. The opportunity to see the whole context with all available information, objects, topics and relations from different areas helps to avoid wrong decisions aimed just at a local optimisation. Due to this fact, company can improve its performance and competitiveness faster and more easily. Clear visualisation of all topics and their associations enables to suggest in which areas the proposed improvement or innovation could cause a problem. These potential threats can be easily verified based on the knowledge recorded by any user. One of the possibilities of how to simplify and automate this process is to integrate Event-B proof obligations into KMS (in our case into ATOM).

Event-B is a refinement-based formal modelling method for developing discrete transition systems. It extends and simplifies B-method (Abrial, 1996; Abrial \& Hallerstede, 2007; Abrial, 2010). As Hallerstede (2008) states, creating models in Event-B should help reasoning and understanding around complex models. Therefore, it is a useful tool for decision-making.

When implementing a suggested innovation in order to eliminate some kind of waste and create a higher value for final customers, this decision can have a negative impact on another area of Lean enterprise. It is a problem associated with focusing on local optimisation instead of considering a global environment. In the next section, we introduce a simplified Event-B model that extends the previous example (from section 3.2.) and shows the possibilities of Event-B modelling in combination with KMS.

\subsection{Problem Formulation}

We described several improvements on two production lines in our previous example. Some are definitely positive. However, others can be contradictory. For example, reduction of the manufacturing batch can cause higher transportation costs, or new machinery can cause increasing costs because of for its maintenance. Therefore, each suggested innovation should be considered from a global viewpoint and its impact on the whole lean enterprise.

The most common evaluation approaches are based on a total profit (before interest, taxes and depreciations) or contribution margin, which is influenced by total sales and total (or just variable) costs. Consider ci as a total cost in a cost centre $i$ and $s j$ as total sales of a product $j$. Then, the total profit $\mathrm{P}$ can be described as follows:

$P=\sum_{j=1}^{m} S_{j}-\sum_{i=1}^{n} c_{i}$ 
Each innovation causes one or more changes in total sales or total costs. Therefore, it should be accepted in case the final change of total profit is positive:

$\Delta P=\sum_{j=1}^{m} \Delta s_{j}-\sum_{i=1}^{n} \Delta c_{i}$

In short, our sample company produces just three products and all costs are classified into five cost centres: personal expenses, energies, material expenses, transportation and stock-keeping.

\subsection{Simple Basic Event-B Model}

For the purpose of Event-B modelling, our problem must be defined by (Abrial, 2010):

- a set of constants and their axioms in an Event-B component called context and

- a set of variables and invariants that are inserted directly into the main Event-B component called machine.

In our simplified example, it is not necessary to define any constants if there is no limitation regarding a minimum required positive effect from implemented innovation. However, if the company's strategy requires some minimum positive change in profit, it can be described via Event-B context component as follows:

$\begin{array}{rll}\text { CONTEXT } & \text { Profit Change } & \\ \text { CONSTANTS } & \min P & \text { // minimum required profit change } \\ \text { AXIOMS } & & \min P \in \mathbb{N} 1 \\ \text { END } & \text { axm1: } & \end{array}$

Axiom is used to test a minimum required profit change which is represented by an integer value. The event- $\mathrm{B}$ method describes the main context of a problem and all possible events in the form of general knowledge-based statements and hypotheses. Its connection with the real database (e.g. a database of transaction systems) offers an extremely strong and fault-resistant tool for automating decision-making activities to increase its efficiency.

In the next stage, it is necessary to define all variables and invariants that describe the state of a machine and all important characteristics. The number of variables and invariants depends on the complexity of a problem and the level of detail required. In our example, we used total sales of three selected products and five cost centres (personal expenses, energies, material, transportation and stock-keeping). Invariants explain relations between all variables and their data types. After the implementation, the Event-B model loads real-time data for each variable from transaction systems or other types of technologies used. All variables are given an initial value via a special event called initialisation, which must be defined at the beginning. Constants and axioms are imported from the context via SEES clause. In our example, variables, invariants and initialisation values are defined as follows: 


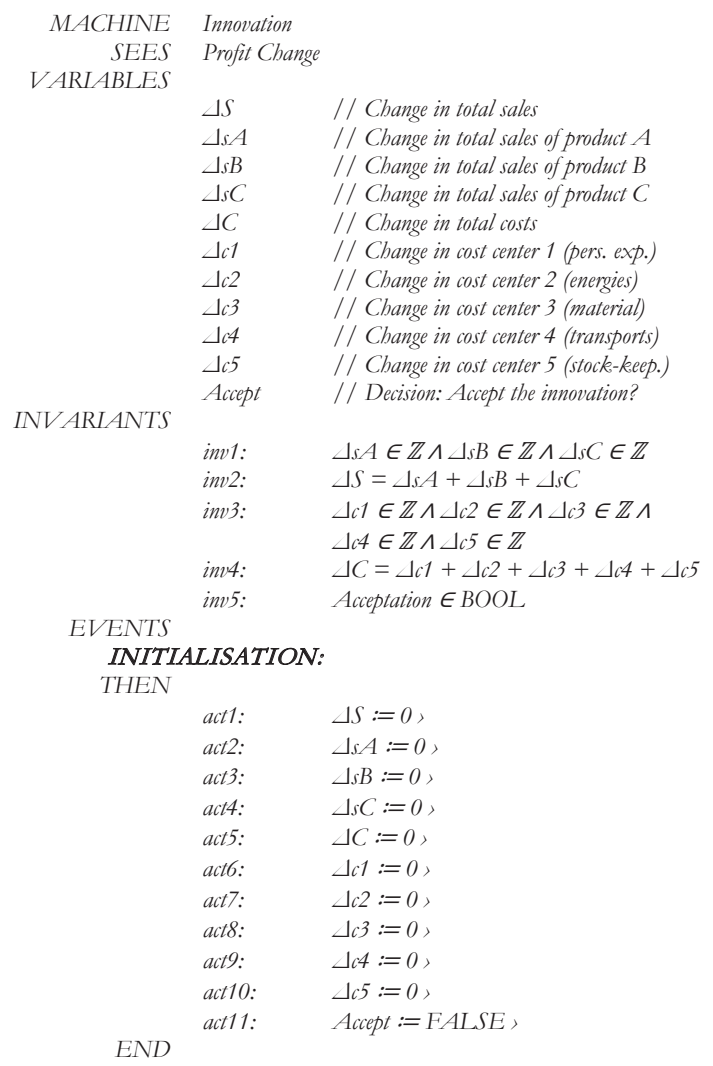

Then, each suggested innovation is a separate event, which can be modelled and proved by the RODIN platform (platform for Event-B modelling) in order to make the right decision about its acceptance (Métayer et al., 2007). It is necessary to define so-called guards for each event. Guards are testing the level of fulfilling our goals set. In our example, you can see a guarded event, where the software application is checking whether the sum of all positive changes in sales $(\Delta \mathrm{s} \mathrm{A}+\Delta \mathrm{sB}+\Delta \mathrm{s} C)$ is higher than the sum of all negative changes in all cost centres $(\Delta \mathrm{c} 1+\Delta \mathrm{c} 2$ $+\Delta \mathrm{c} 3+\Delta \mathrm{c} 4+\Delta \mathrm{c} 5)$. In case of a positive result, the innovation is accepted, otherwise rejected.

EVENT: Suggested Innovation (success):

WHERE

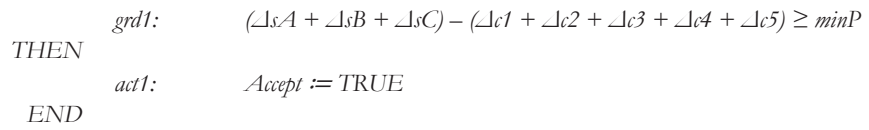

EVENT: Suggested Innovation (failure):

WHERE

$\begin{array}{lll} & \text { grd1: } & (\Delta s A+\Delta s B+\Delta s C)-(\Delta c 1+\Delta c 2+\Delta c 3+\Delta c 4+\Delta c 5)<\min P \\ \text { THEN } & \text { act }: & \text { Accept }:=\text { FALSE }\end{array}$

END 
Our model is a simple shortened example showing how Event-B modelling can be used for evaluating a potential improvement or innovation influencing the company's competitiveness. However, the real situation is often much more complicated than in the example presented. It includes many exceptions and constraints that are not clearly known at the beginning. Therefore, a great advantage of Event-B modelling is the possibility of introducing refinements that easily introduce all new information, details and system complexity into an existing model (Métayer et al., 2007).

\section{CONCLUSIONS AND DISCUSSION}

In this paper, we documented how suitable information support can help to solve various lean projects in a more efficient way and reach a more competitive position. The core idea was introduced on a simple example of production process improvement or innovation. A lean enterprise focuses on a continuous increase of added value and identifying and eliminating all kinds of waste not just in the production process itself. It includes continuous permanent improvement and applying various innovations based on the idea of eliminating waste. However, sometimes, when considering some local problems, our decision can cause another more serious problem than that originally solved. Therefore, an efficient and intensive communication between all departments involved is important.

In the first part of the paper, with a case study of support processes outside the IS, we introduced an ontology-driven knowledge management system that helps to improve internal communication and sharing data in different areas of a business. There is the possibility of creating a socalled mini-application focused on a special area, in our case, the process innovation. This idea is illustrated by an example from a real production company.

However, as discussed, this application cannot evaluate the efficiency of the innovation proposed for production process improvement. It cannot stop decision-making automatically in case of a potential threat of negative effects of a new idea proposed. This is why we sought to illustrate how it can be improved upon by implementing some automatic mechanism in the form of expert systems that are able to make some basic decisions automatically. In our case, we used proof obligatory Event-B modelling, which is a powerful tool for formal system development via stepwise refinement.

Our current and future research activities are aimed at a more complex solution to production planning and control, which is completely based on Event-B modelling. It is a new powerful tool that can be applied in any area of business processes in order to improve their performance or even the company's competitiveness. Subsequent findings will be periodically published in scientific journals and conference proceedings.

\section{Acknowledgements}

The research related to this paper was supported by the RVO project "Modelling of effective production and administration processes parameters in industrial companies based on the concept Industry 4.0", run by the Department of Industrial Engineering and Information Systems, Faculty of Management and Economics, Tomas Bata University in Zlín, Czech Republic. 


\section{References}

1. Abrial, J. R. (2010). Modeling in Event-B: System and Software Engineering, 1st ed. Cambridge University Press.

2. Abrial, J. R. (1996). The B-book: Assigning programs to meanings. Cambridge University Press.

3. Abrial, J. R., \& Hallerstede, S. (2007). Refinement, Decomposition and Instantiation of Discrete Models: Application to Event-B. Fundamentae Informatica, 77(1-2), 1-24.

4. AION CS (2012). Aion Topic Maps Engine ATOM, [online], 2012 [cit. 2016-07-25]. Retrieved from http://www.aion.cz/.

5. Cerny, J. (2012). Lean companies support. IT Systems, 14 (9), 18-19.

6. Cvrkal, M. (2012). Enterprise IS for production companies. IT Systems, 14(9), 12-13.

7. Dudbridge, M. (2011). Handbook of Lean Manufacturing in the Food Industry. New Jersey: Blackwell Publishing.

8. Hallerstede, S. (2008). On the Purpose of Event-B Proof Obligations. Abstract State Machines. Computer Science, 5238, 125-138. http://dx.doi.org/10.1007/978-3-540-876038_11.

9. Chromjakova, F., \& Rajnoha, R. (2012). Potentials of Information and Organisational Process Improvement through Trained Office Staff. Journal of Competitiveness, 4(1), 69-82. https://doi.org/10.7441/joc.2012.01.06.

10. Imai, M. (2004). Kaizen. 1st ed., Brno: Computer Press.

11. Jackson, P. (1998). Introduction To Expert Systems. 3rd ed., Boston: Addison Wesley.

12. Klečka, J., \& Matějka, M. (2004). Nové podnikové systémy. Praque: Oeconomica.

13. Métayer C., Abrial J-R. \& Voisin L. (2007). Event-B language, 2005. RODIN Project Deliverable 3.2. Deploy Project.

14. Mikulášková, M. (2013). Application of the Industrial Engineering Methods in the Optimization of the Product Line. Zlín: Tomas Bata University in Zlín.

15. Mu Ch. (2013). On Information Flow Control in Event-B and Refinement. In Proceedings of the International Symposium on Theoretical Aspects of Software Engineering. (pp. 225-232). New York (USA): IEEE. . http://dx.doi.org/10.1109/TASE.2013.43.

16. Pepper, S. (2012). The TAO of Topic Maps. Ontopia, [online], 2012 [cit. 2016-07-15]. Retrieved from http://www.ontopia.net/topicmaps.

17. Pereverzeva I., Troubitsyna E. \& Laibinis L. (2012). Development of Fault Tolerant MAS with Cooperative Error Recovery by Refinement in Event-B. In Proceedings of DS-EventB 2012: Workshop on the experience of and advances in developing dependable systems in Event-B, in conjunction with ICFEM. Kyoto (Japan): ICFEM.

18. Petr, J. (2013). Process management out of the information system. IT Systems, 15(4), 16-17.

19. Rasmussen, B.M. (2015). Creating an Innovation Culture. The Benefit is Lower Costs, Faster Processes, and Higher ROI. Red Associates, [online], 2015 [cit. 2016-06-15]. Retrieved 
from http://www.redassociates.com/conversations/enabling-innovation/.

20. Sayar I. \& Bhiri M. T. (2014). From an Abstract Specification in Event-B toward an UML/ OCL Model. In Proceedings of the 2nd FME Workshop on Formal Methods in Software Engineering (pp. 17-23). New York (USA): ACM. https://doi.org/10.1145/2593489.2593494.

21. Smith, R. \& Hawkins, B. (2004). Lean Maintenance: Reduce Costs, Improve Quality, and Increase Market Share. 1st ed. Amsterdam: Elsevier Inc.

22. Smith, R. (1985). Knowledge-Based Systems: Concepts, Techniques, Examples. Cambridge: Schlumberger-Doll Research.

23. Vaculíková, E. (2011). Layout of the Product Hall. Zlín: Tomas Bata University in Zlín.

24. VUE (2015). Visual Understanding Environment [online], 2015 [cit. 2015-05-25]. Available at http://vue.tufts.edu/.

25. Weiss et al. (1986). Empirical Analysis and Refinement of Expert System Knowledge Bases. In Proceedings of the Annual Symposium on Computer Application in Medical Care (pp. 53-60). https://doi.org/10.1007/978-1-4613-8777-0_12.

\section{Contact information}

Prof. Ing. Ladislav Burita, CSc.

Tomas Bata University in Zlin, Faculty of Management and Economics Mostni 5139, 76001 Zlin, Czech Republic

Email: burita@fame.utb.cz.

Ing. Denisa Hrušecká, Ph.D.

Tomas Bata University in Zlin, Faculty of Management and Economics Mostni 5139, 76001 Zlin, Czech Republic

Email:brusecka@fame.utb.cz.

Ing. Michal Pivnickea, Ph.D.

Tomas Bata University in Zlin, Faculty of Management and Economics Mostni 5139, 76001 Zlin, Czech Republic

Email:pivnicka@fame.utb.cz.

Ing. Pavel Rosman, Ph.D.

Tomas Bata University in Zlin, Faculty of Management and Economics Mostni 5139, 76001 Zlin, Czech Republic

Email:rosman@fame.utb.cz. 